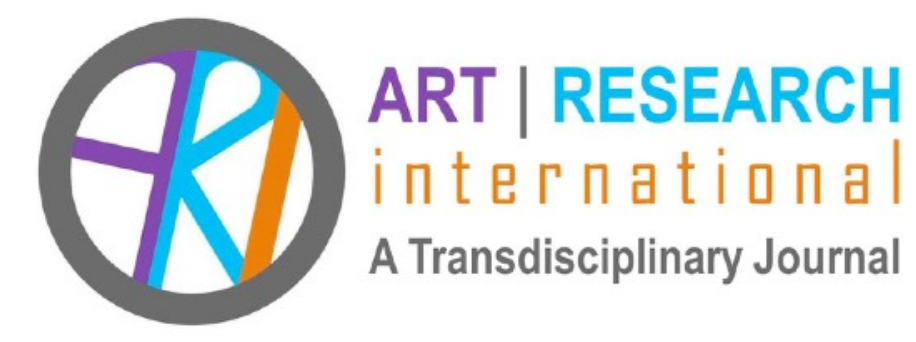

\title{
TRAUMA-SENSITIVE PEDAGOGY \& PRACTICE NEWSLETTER 1 (OF 2)
}

\author{
Alexandra Fidyk \\ University of Alberta \\ fidyk@ualberta.ca \\ Mandy Krahn \\ Brightview School \\ mandy.krahn@epsb.ca \\ Vessela Balinska-Ourdeva \\ Harry Ainlay High School \\ vessela.Ourdeva@epsb.ca \\ Karen Jacobsen \\ McNally High School \\ kjacobse@ualberta.ca \\ Alison Brooks-Starks \\ The Waldorf Independent School of Edmonton \\ alisonbrooksstarks@gmail.com
}

Alexandra Fidyk, PhD, Professor Department of Secondary Education, $U$ of A, SK Certified Teacher, Certified and Registered: Jungian \& Integrated Body Psychotherapist; Inherited Family Trauma \& Constellations; Somatic Experiencing (in training Advanced 
1). Expertise: Buddhist meditation/mindfulness; poetry, writing; expressive arts; trauma studies and socially-engaged pedagogy.

Mandy Krahn, PhD(C), ATA Certified Teacher, Art Therapist, School Counsellor, Assistant Principal, Brightview School. Expertise: Certified Yoga Instructor; visual artist; expressive arts; arts-based research with children and youth; Indigenous curriculum and pedagogy.

Vessela Balinska-Ourdeva, PhD, ATA Certified Teacher, IB Extended Essay Coordinator, Harry Ainlay High School. Expertise: modern languages \& cultural studies; Jungian-inspired pedagogical approaches, including the symbolic, archetypes, feeling function; poetry, writing; trauma studies; year-one of Integrated Body Psychotherapy for Allied Professionals.

Karen Jacobsen, PhD(S), ATA Certified Teacher, ELA Department Head \& IB Certified Teacher, McNally High School. Expertise: Certified Yoga Instructor (Ashtanga, Yin, Restorative); Black Belt Certification in Wing Chun Kung Fu; contemplative practices; Buddhist meditation/mindfulness; wildlife photography; writing.

Alison Brooks-Starks, BEd, ATA Certified Teacher, Outdoor Education Waldorf Independent School of Edmonton. Expertise: Certificate of Spiritual Care; Outdoor Spiritual Education; Nature \& 2SLGBTQ Activist; Certificate in Ecopsychology.

Abstract: This publication includes the first of two newsletters published in this issue of Art/Research International. This second newsletter is followed by a commentary and references for both newsletters.

Attentive to local and global mental health realities and the emergent need to provide intercultural mental health perspectives, resources, and methods that work across cultures in school contexts, I (the first author) conducted a participatory poetic inquiry, "Image, Body, and Voice: Supporting Girls' Sense of Wellbeing," with grade-6 girls in an inner-city school in Alberta. It sought to: (i) meet new Teacher Quality Standards (TQS) "to build positive and productive relationships with students [and] peers" (AB Education, 2018, p. 4); and (ii) be "aware of and facilitate responses to the emotional and mental health needs of students" (p. 6). I was guided by the following research question: In what ways might girls' experiences with art-integrated activities and body-centred methods inform educators about pedagogical practice and mental health interventions? 
Findings indicated the transdisciplinary praxis that emerged-arts-based, contemplative and somatic methods-enhanced the girls' sense of self and wellbeing. The youth reported that these activities had explicit value: sharing circles used for check-ins and outs, ceremony-which welcomed witnessing-relational and body-centred practices, and one-on-one time with the $\mathrm{PI}$. The life-size body maps as research creation illustrated that the participants learned to externalize sensations and emotions in a safe way, aiding them in the development of skills needed for emotional self-regulation. Body maps broadly defined are life-size body images, while body mapping is the process of creating body maps using collage, photography, painting, or other arts-integrated methods to visually symbolize aspects of people's lives, their bodies, and their worlds.

Funding from Research Impact Canada, VP Research \& Innovation University of Alberta and the Kule Institute for Advanced Study aided to mobilize evidence-informed knowledge from this research through professional community engagement with preservice teachers at a full-day workshop. Presenters at the workshop were members of a Community of Professional Practice (COPP) where the activities of educational research and trauma-sensitive practices were shared, including culturally aware methods for diverse populations. This newsletter reflects one of two events and two research creation artifacts provided as follow up to the attendees.

Keywords: social emotional needs; mental health; trauma; play; imagination; vagus nerve; emotional regulation; body maps; self awareness; arts-based methods 


\section{Trauma-Sensitive Pedagogy \& Practice}
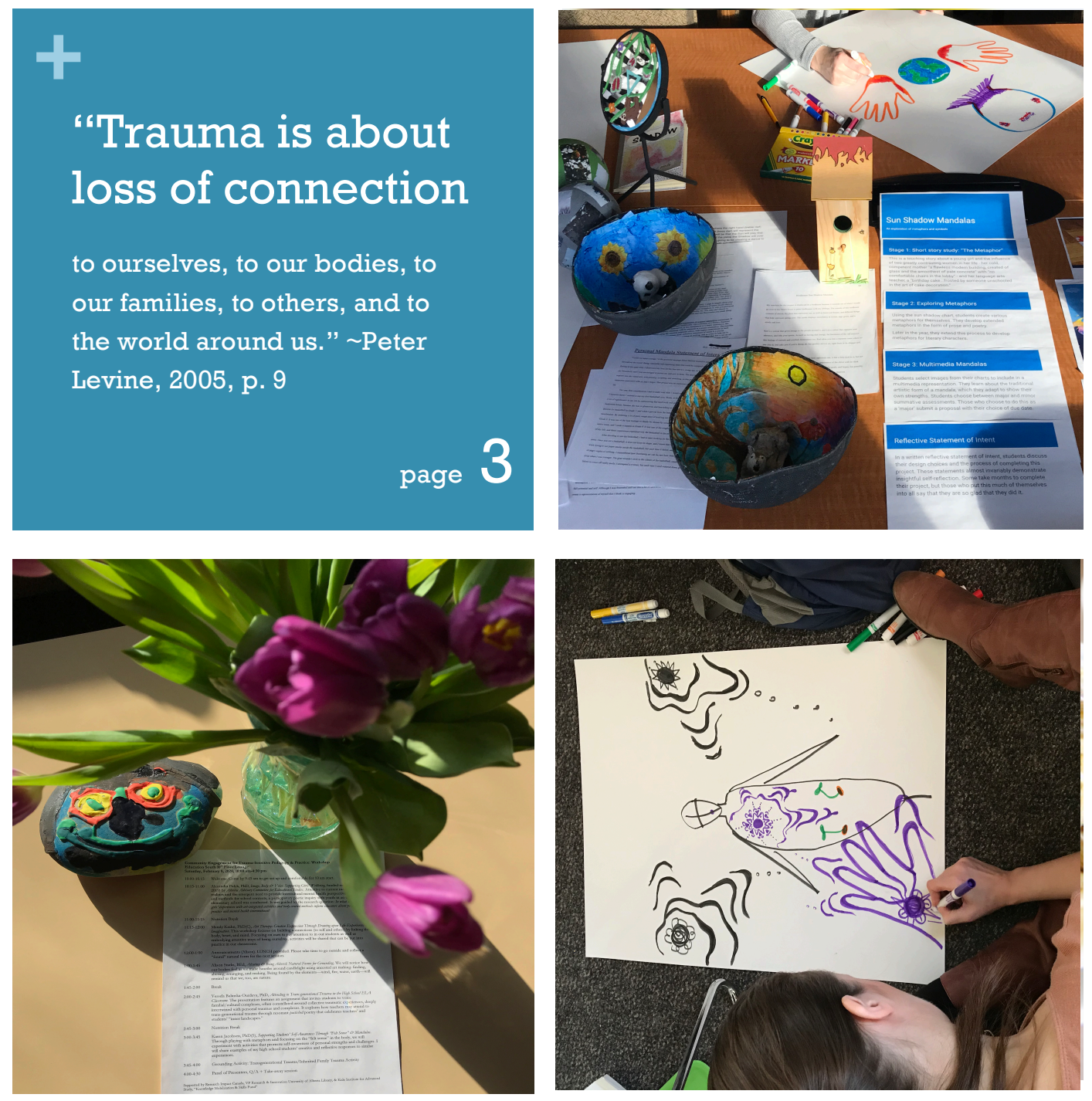

Teaching Method:

Pastiching

Pastiche is a literary

technique that leads to

the production of an

original work, but in

the style of another

text. Mimicking the

authorial choices of a

writer often is an

effective way to

appreciate how his or

her artistic pieces

work. This technique

encourages close

attention to Dumont's

style, for example,

and pays homage to

her art by writing an

original poem about

one of your own

ancestors. See:

Marilyn Dumont

(2015), The Pemmican Eaters

\section{"At the core of} recovery is self awareness. . . .

Body awarness puts us in touch with our inner world ... [with-out such awareness and the ability] to observe the interplay between your thoughts and your physical

sensations," there can be no healing.

Bessel van der Kolk, 2014, pp. 208-9

\section{Community Engagement: Workshop}

The research project, "Image, Body, and Voice: Supporting Girls' Sense of Wellbeing," conducted August 2017-2019, at an inner-city elementary school in Alberta, was funded by an Alberta Advisory Committee for Educational Studies (AACES) grant. It sought to: (i) meet new Teacher Quality Standards (TQS) "to build positive and productive relationships with students, parents/caregivers, peers, and others in the school and local community" (AB Education TQS,
2017, p. 4); (ii) be aware of and facilitate "responses to the emotional and mental health needs of students" (p. 6); (iii) contribute to "inclusive education, including welcoming, caring, respectful and safe learning environments" (p. 6); and (iv) address "respectful relations, health, and wellbeing" of students, teachers, and staff of Edmonton public schools as prioritized in the Faculty of Education's Strategic Plan 2019-2024 (p. 13). (continued) 


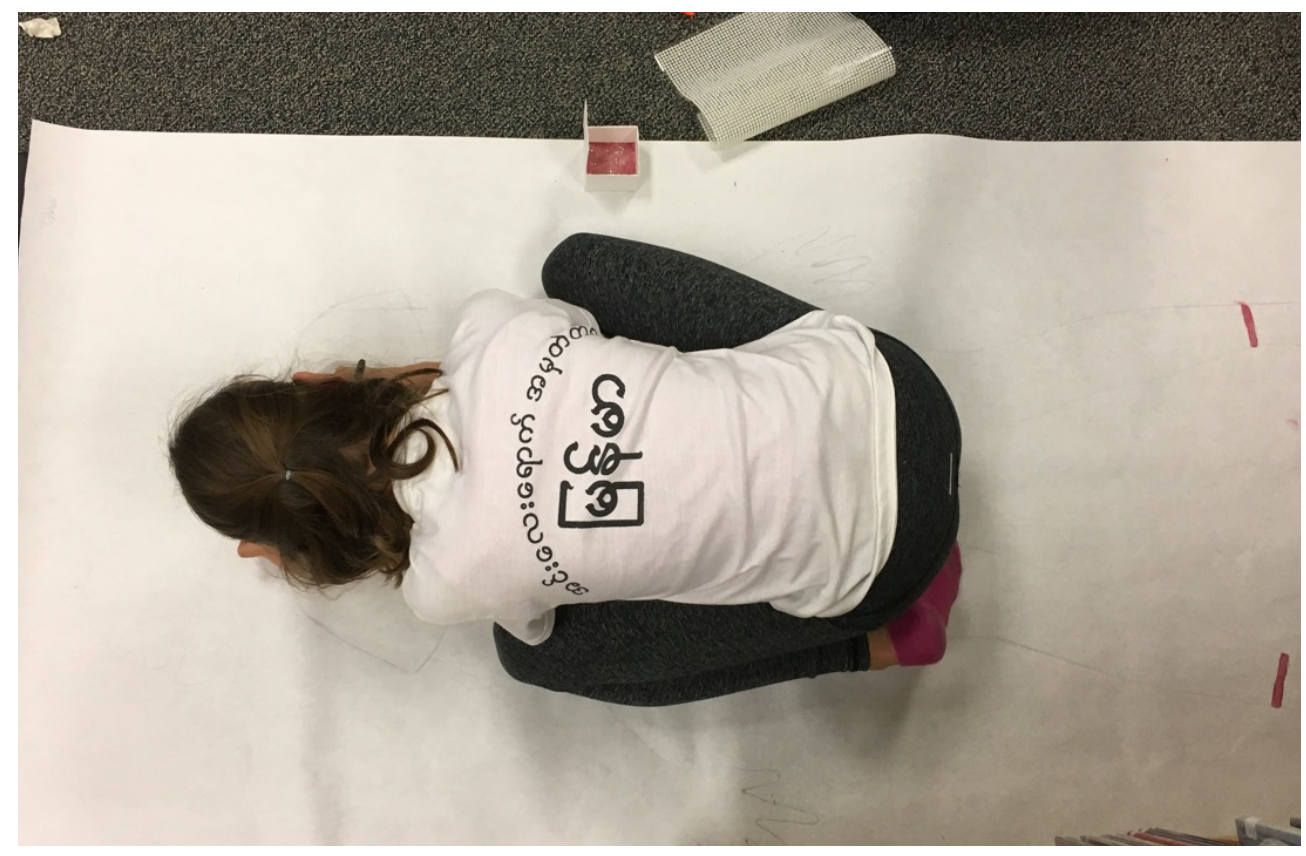

Body mapping is a decolonizing method. It privileges felt sense and empowers through voice.

\section{TSPP Workshop for Pre-Service Teachers}

Attentive to local and global mental health realities and the emergent need to provide intercultural mental health perspectives, resources, and methods that work across cultures in school contexts, I conducted a participatory poetic inquiry with eight grade-6 girls across four months, meeting biweekly. We were guided by the following research question: In what ways might girls' experiences with art-integrated

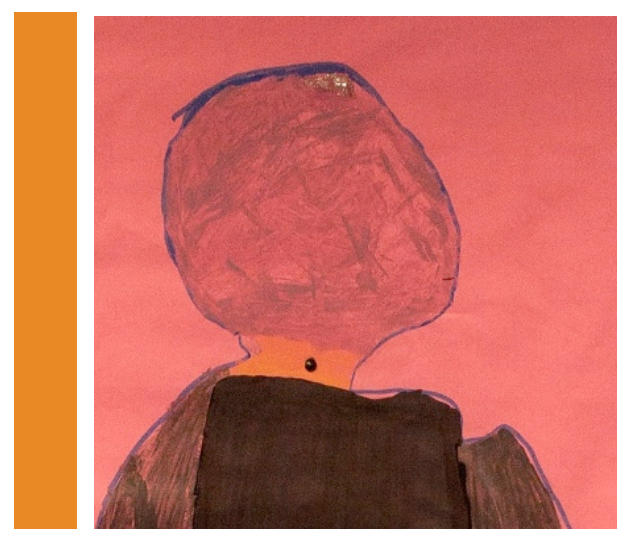

activities and body-centred methods inform educators about pedagogical practice and mental health interventions? The study was located in an animated paradigm-that is, a worldview that recognizes and values dreams, affect, intuition, images, imagination, body, and feeling. It honours the unconscious, imaginal, emergent, transgender, transpersonal, transgenerational, and the ancestors. Here the world is alive, discontinuous, and in flux. Somatic,

reported that the participants were more confident and socially engaged with their peers during and outside of class time, and in one case a new voice social justice rose. While the data creation phase integrated many methods, the ways in which the girls responded to particular methods, practices, and skills led to the emer- contemplative and arts-integrated methods were woven into each of the six 150-minute meetings for data creation and data collection. Here a symbolic approach led the work while informed by trauma studies, in particular psychodynamic and neurobiological perspectives. Teachers

\section{Trauma is any experience} that causes a person unbearable psychic pain or anxiety. $\sim$ Kalsched, 1996

gence of a specific sequence and timing of methods. Body mapping with symbols depicted their inner landscapes. The life-size body maps illustrated that the participants learned to externalize sensations and emotions in a safe way. Doing so aided in the development of skills needed for emotional self-regulation. 

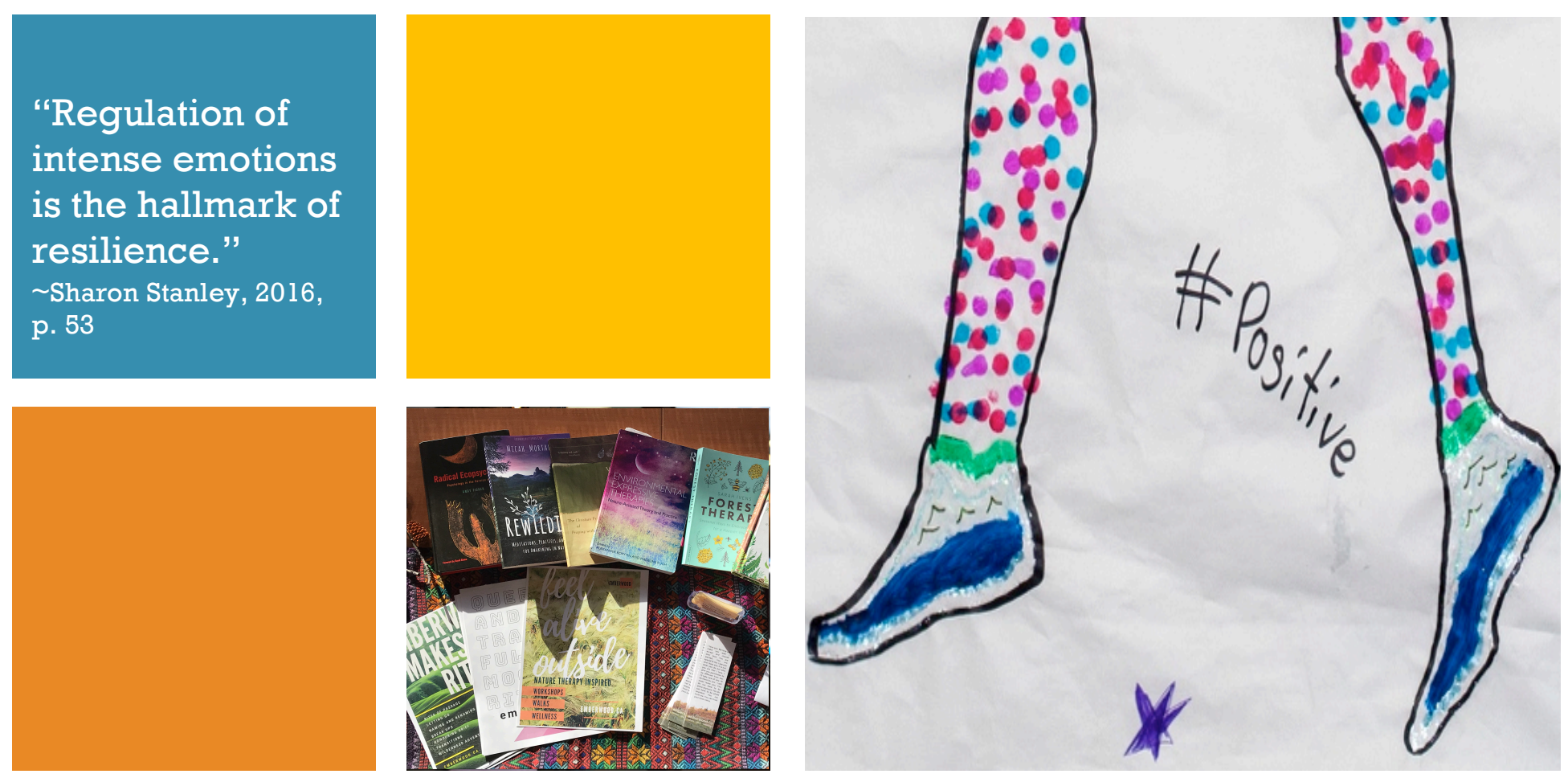

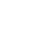

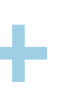

\section{Emotional Regulation: When you are self-regulated...}

You can aid another to gain regulation of their autonomic nervous system. How can you self-regulate? What brings you to a calm state? At school, home, work or even on the bus:

$>$ Find/create a quiet safe space;

> Structure class/activities for predictability so to foster a sense of safety;

$>$ Take time to share;

$>$ Be consistent;

$>$ Get socially engaged in meaningful ways;
> Take care of an animal, a plant;

$>$ Stretch gently; do yin yoga;

> Pause; take breaks;

$>$ Provide clarity of expectations;

$>$ Greet children/family/colleagues by name every day;

> Make time for face-to-face contact;

$>$ Build relationships;

> Engage in rhythms: drumming, qigong, dance, singing, chanting;

(continued) 
$>$ Slow down;

$>$ Be mindful: Get in touch with transitory nature of feelings;

$>$ Enhance positive affect;

$>$ Engage in metaphoric thinking; integrate symbols, images, sensations, feeling (inner valuation), affect...;

$>$ Read poetry aloud;

> Drink water; have a snack;

$>$ Use "soft eyes" (not intense or sharp) to make contact;

> Plant herbs, flowers or make window boxes and gardens;

$>$ Orient to your space: Let eyes gently scan until they "find" a form and then name its characteristics (red chair);

> Titrate: Move back and forth gently between that which is intense and that which is not;

> Use weighted blankets or pillows or squeezy balls;

$>$ Listen to soothing music (60 sec beat preferably);

> Be with nature: Take a walk, hug a tree, admire the moon;

$>$ Reframe mindset: Instead of

Trauma is "a moment that tears into the course of normative living, altering the very bounds of identity." Lombardi \& Gordon, 2014, p. 172
"I have to..." try "I get to...";

$>$ Keep a journal;

$>$ Engage in creative process: Colour, collage, build, knit, paint, draw, weave, sew;

$>$ Exercise, ride a horse, swim;

> Play in a sandbox, swing:

> Talk with a caring friend;

$>$ Handwrite a personal letter;

$>$ Be imaginative;

> Stretch gently, do yin yoga;

$>$ Check-in with others: "How do you feel?" Then, "How do you notice that?" (not why)

$>$ Sip hot tea in a beautiful cup.

Once regulated, you can resume previous activity. Only when we return to the present moment, an embodied state, is learning at its optimal condition.

\section{"[A] child does not}

sit at her desk alone. Her grandparents, their secrets, their lands (home, exile, refugee), and the events that enfold their lives - in other words, their fates-accompany her" (Fidyk, 2016, p. 196). The ancestors "not only animate us," but their unanswered questions become powerful forces to influence our own decisions and choices (Hillman \& Shamdasani, as cited in Fidyk, 2016, p. 196).
Ask yourself: "What

sensations in my

body tell me that

I'm feeling okay?'"

Tingles, twitchy, wooden,

queasy, spacey, airy, achy,

tight, knotted, icy, blocked,

wobbly, chilly, hot, hollow,

expanded, light, fluid,

numb, spikey, bubbly,

energized, soft, lively, dull,

sharp, breathless, wiggly,

leaden, calm, rigid, twisted,

jagged, barbed, soothing...

Notice; Name; and Track

Sensation. Observe change.

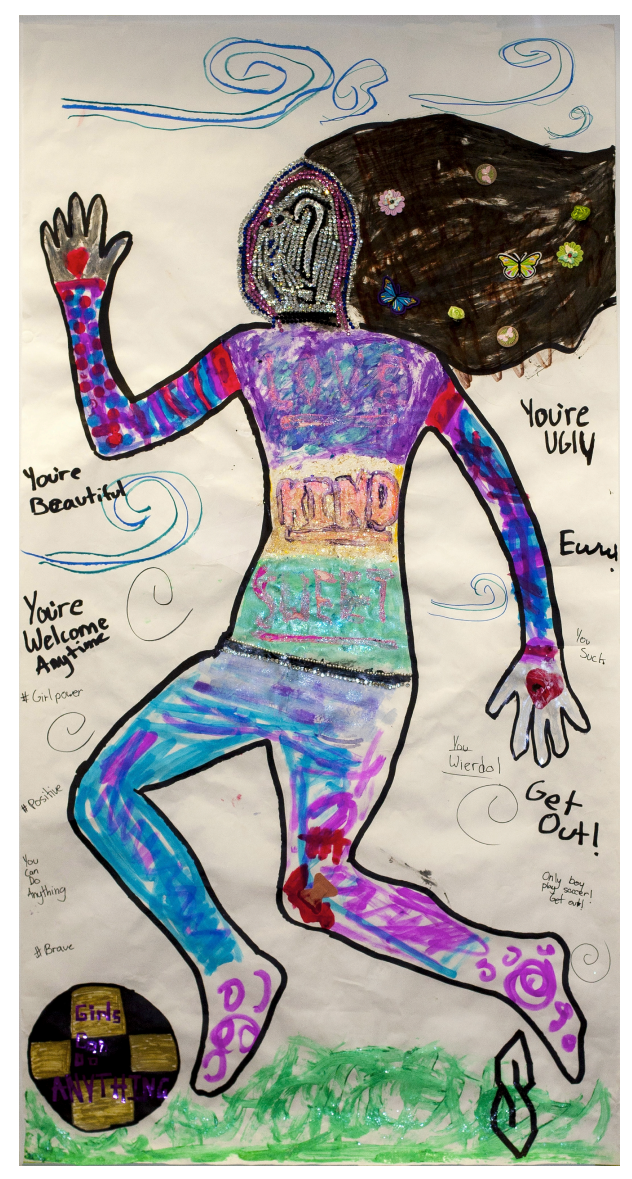



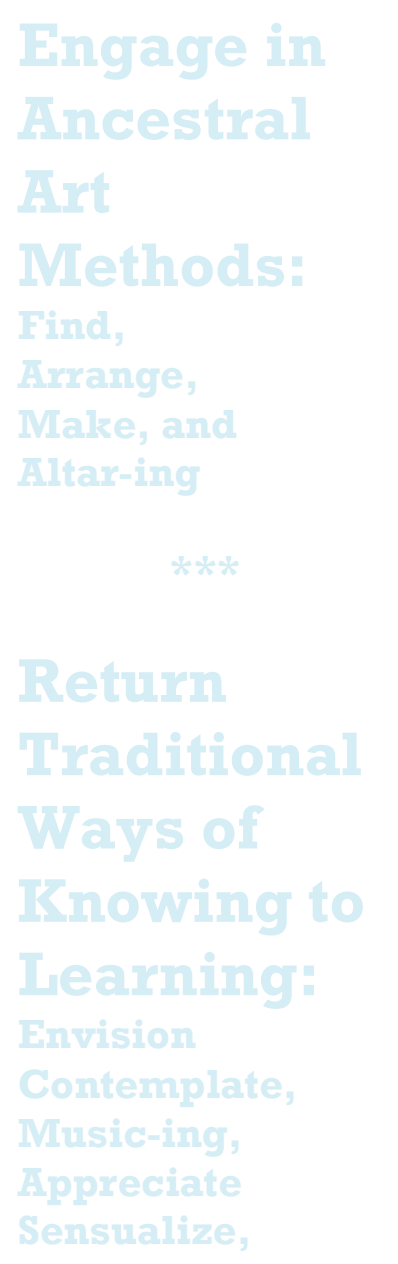

IVuse,

IVythologize,

Dream,

Wait:

Tend,

Eroticize,

Journeying,

Poeticize,

Anplify,

Ritualize,

Animate,

Bodily-feel,

Soul-ing,

Play,

Reverencing;

Triclkster-ize,

Spiritualize,

IVagic-malking,

Wonder,

Pray:

Give Gratitude,

Homing .
Expressive Therapies Continuum (ETC)

A structure that allows Art Therapists to creater a starting place for therapy, treatment goals, and pathways for change.

Begin with a client's preferred component \& then move either horizontally or vertically, depending on their therapeutic needs.

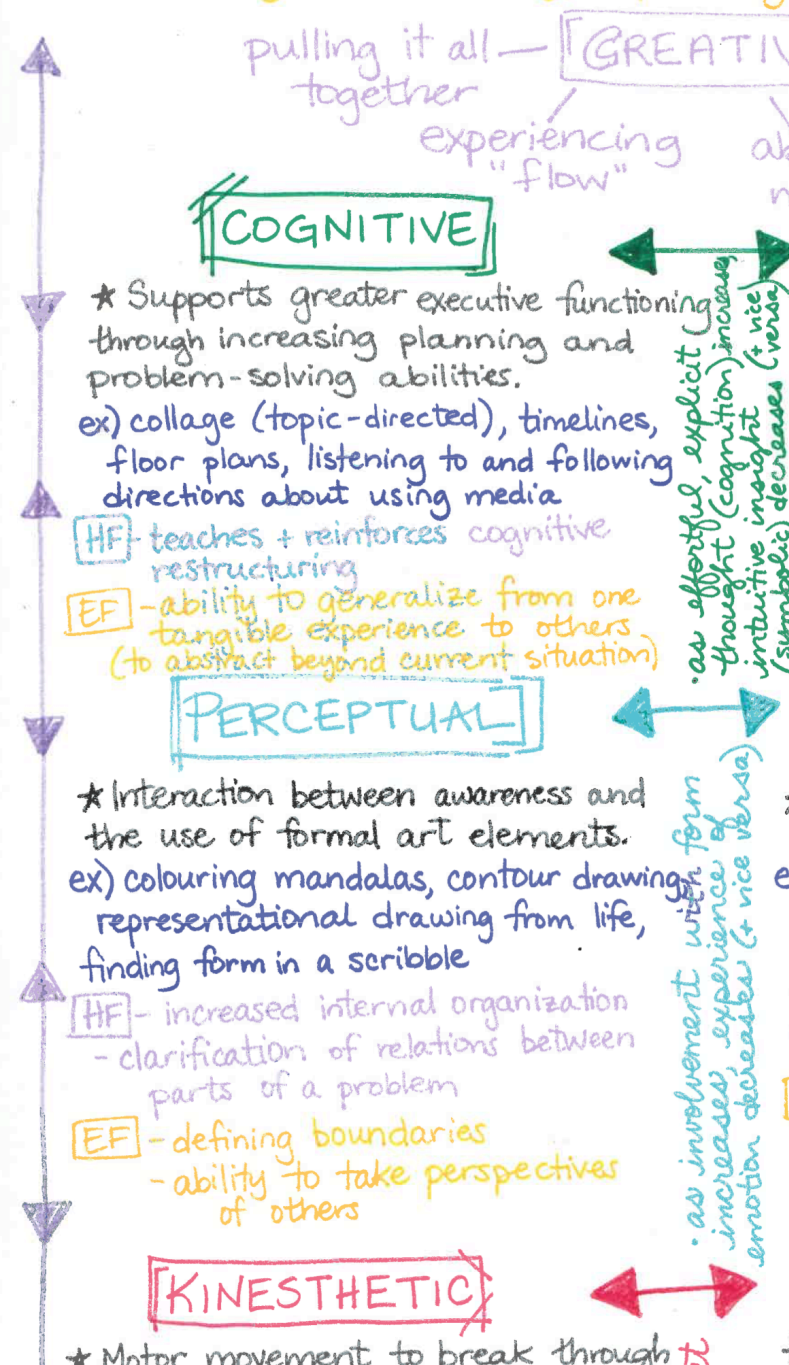

* Motor movement to break through $\$$ physical \& psychological numbing. ex) forceful work with hard clay or

scribbles on large paper, creating to music, tearing paper HF-Release of tension or energy 5 exploration with eyes closed. L - Finding inner rhythm \& EF-perception of form

\section{SENSORY}

* Promotes self-soothing. * Aids in sensory integration. ex) work with soft/wet clay, textile work, finger painting, blending Interaction between awareness and the experience of emotions. ex) body map of feelings/sensations, splurge of errotion (mood states), depiction of primary emotions HF- identification of emotions and understanding their purpose/function EF-ability to express and soothe emotions appropriately to specific aromas, sensory exploration with eyes closed. HF. Matching internal 4 external

EF-Awareness + experience

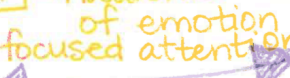

* Definitions and examples organized HF = Healing Function $E F=$ Emergent Function by Mandy Krahn, For further information, see texts \&े articles by Lisa Hinz: Expressive Therapies Cont. Chart outline from L. D. Hinz (2015), p. 46 


\section{References \& Recommended Reading}

Fidyk, A. (2019). Trauma-sensitive practice for new teacher standards: Addressing the epidemic of our times. https://ineducation.ca/ineducation/article/view/431/983

Fidyk, A. (2016). Unconscious ties that bind: Attending to complexes in the classroom, part 1. International Journal of Jungian Studies, 8(3), 181-194.

Fidyk, A. (2016). Unconscious ties that bind: Attending to complexes in the classroom, part 2. International Journal of Jungian Studies, 8(3), 195-210.

Hinz, L. D. (2015). Expressive therapies continuum: Use and value demonstrated with case study. Canadian Art Therapy Association Journal, 28(1-2), 43-50.

Kalsched, D. (1996). The inner world of trauma: Archetypal defenses of the personal spirit.

Kalsched, D. (2013). Trauma and the soul: A psycho-spiritual approach to human development and its interruption.

Levine, P. (2015). Trauma \& memory. Brain and body in a search for the living past.

Linklater, R. (2014). Decolonizing trauma work: Indigenous stories and strategies.

Lombardi, K. L., \& Gordon, A. (2014). Life after "death": An empirical and clinical perspective on trauma. In O'Loughlin \& Charles (Eds.). Fragments of trauma and the social production of suffering: trauma, history, and memory (pp. 169-184).

Stanley, S. (2016). Relational and body-centered practices for healing trauma: Lifting the burdens of the past.

van der Kolk, B. (2014). The body keeps the score: Brain, mind, and body in the healing of trauma.
Felt sense is a

combination of

emotion, awareness,

intuitiveness, and

embodiment.

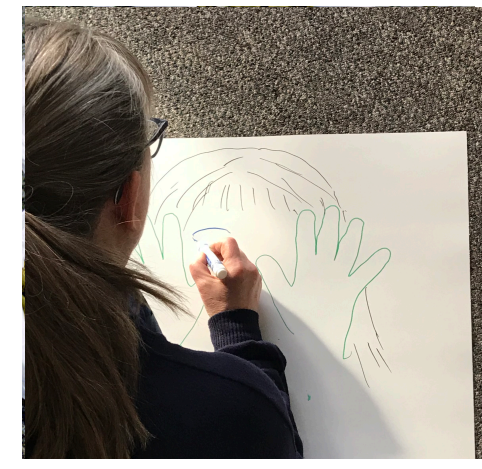

Aid Students to

Transition to

Learning: With yoga

or stretching, music, 5

sec inhale/5 sec exhale,

laughter, a welcoming

greeting, colouring, a

moment of mindfulness.

Inkshedding: to

shed ink through

free writing in

response to a

literary prompt or

beautiful words.

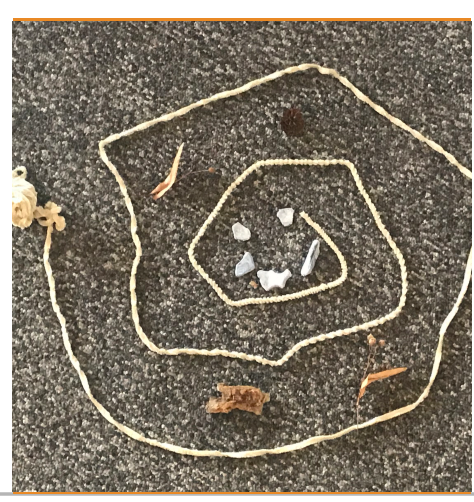

\section{Alexandra Fidyk, Principal Investigator}

Associate Professor |Department of $i$ ecunluar y suucallur University of Alberta, Edmonton, AE fidyk@ualberta.ca

\section{[Recipient]}

Address line 1

Address line 2

Supported by Research Impact Canada, VP Research \& Innovation University of Alberta, \& Kule Institute for Advanced Study, "Knowledge Mobilization \& Skills Fund" 